\title{
The Application of Scientific Classification Method and Its Value in Chemistry Education
}

\author{
Chengyin Yang, Xueqing Shen, Sixin Li \\ School of Chemistry \& Chemical Engineering, Shaanxi Normal University, Xi'an, China
}

Email address:

yangcy@snnu.edu.cn (Chengyin Yang)

\section{To cite this article:}

Chengyin Yang, Xueqing Shen, Sixin Li. The Application of Scientific Classification Method and Its Value in Chemistry Education. Science Journal of Education. Vol. 4, No. 6, 2016, pp. 181-185. doi: 10.11648/j.sjedu.20160406.13

Received: September 30, 2016; Accepted: October 11, 2016; Published: November 16, 2016

\begin{abstract}
The promotion of basic education curriculum reform makes teachers gradually focus on all aspects of the development of students including the mastery of knowledge, learning process and method and developing emotional attitudes and values. The classification method and its thought are significant in secondary school chemistry. However, it doesn't show its real value in the reality of teaching. From the perspective of the professional development of chemistry teachers in secondary school, this paper elaborates that teachers should be conscious of comprehensive and systematic chemical classification learning, since requiring students to master the knowledge of the classification and its results is far from enough. The classification is fully understood from the classification of ontology, values and application values (taking chemistry for example). Teachers can consciously penetrate classification method and its thought to students after tracing the source knowledge of classification. Even if there is no text provision expressly to stipulate how important classification is. Ultimately, objective of process and method can be implemented.
\end{abstract}

Keywords: Classification, Classification Method, Chemical Classification, Chemistry Teaching, Secondary School Chemistry Teachers, Teacher Professional Development

\section{Introduction}

The classification is very important in high school chemistry education: (1) the requirements of chemistry curriculum criterion: junior high school students should preliminarily use classification to process information, establish the connection of knowledge and know simple element classification [1]. And build up the view of "classification", which is the subject concept after chemistry learning [2]. High school students are asked to use the method, and view the world form it [3]. (2) The position of classification in the textbook: arranged before the study of chemical elements of knowledge despite different versions, shown as table 1 .

Table 1. The Aspect Position of Knowledge on Classification and Element in High School Chemistry Compulsory.

\begin{tabular}{lll}
\hline Version & Location of Classification Knowledge & Location of Element Knowledge \\
\hline $\begin{array}{l}\text { People Education Press } \\
\text { Jiangsu Education Press }\end{array}$ & Chapter II section I Classification of Substances & $\begin{array}{l}\text { Chapter III Metals and Its Compounds } \\
\text { Chapter IV Non-metals and Its Compounds } \\
\text { Chapter II Chemical Substances Obtained from the Sea }\end{array}$ \\
$\begin{array}{l}\text { Shandong Science and } \\
\text { Technology Press }\end{array}$ & Chapter II section I Elements and Classification of Substances & $\begin{array}{l}\text { Chapter III From Mineral to Base Material } \\
\text { Chapter IV Nitrogen and sustainable development } \\
\text { Chapter III Elements in Nature }\end{array}$ \\
\hline
\end{tabular}

The reason of the arrangement in the books is that the classification method is and its thought are both important. It proved that students would greatly improve the understanding of the chemical element knowledge after systematic learning on classification [4]. The ultimate objective of chemistry education is improving students' scientific literacy and chemistry key competency, which includes the important scientific thinking methods, that is 
classification. (3) In chemistry teaching and research: retrieved articles with the theme of "classification" from 1981 to 2016 (May) in Chinese Journal of Chemical Education,
Education in Chemistry, Teaching and Learning Reference for Middle School Chemistry, shown in Table 2.

Table 2. The Figure of Chemistry Teaching Research on Classification.

\begin{tabular}{llll}
\hline Theme & $\begin{array}{l}\text { Application of classification } \\
\text { or cultivation of the thought }\end{array}$ & $\begin{array}{l}\text { The role of classification in } \\
\text { the study of Chemistry }\end{array}$ \\
\hline Results & 16 & 0 \\
\hline Journal & 4 & 0 \\
\hline $\begin{array}{l}\text { Chinese Journal of Chemical Education } \\
\text { Education in Chemistry }\end{array}$ & 15 & 0 \\
$\begin{array}{l}\text { Teaching and Learning Reference for } \\
\text { Middle School Chemistry }\end{array}$ & 0 & 0 \\
\hline
\end{tabular}

Table 2 shows that classification is truly important. Teachers ask students to master the method instead of results of classification since they change their mind on classification [5]. But few have developed into the use of classification to predict the nature of the material; it does not play a good role in the classification. Maybe the reason is that curriculum standard expressly provides classification requirements, but did not explain what the origin and development is, and why it is important.

J. S. Bruner (2016 1915) proposed that a basic concept of the academic field, not only include the mastering of the general principles, but also the attitude and method of learning. After an empirical study, the students' understanding on the chemical science will be greatly improved when they understand the history of classification, its meaning and the application of classification in chemical knowledge [4]. Only middle school chemistry teachers having a real understanding of classification can they consciously infiltrate the classification method and its thought in chemistry teaching without the external force.

\section{Ontology of Classification}

To master the vital scientific thinking mode, it is necessary to figure out the concept of class.

\subsection{The Origin and Development of Class}

When the "class" evolved from the original animal name to the "clan", the meaning of the class became the most primitive and basic meaning of the class. Class means clan, while class means clan. Namely, same clan means same class Observing clans 'attributes formed the concept of class. And that class is based on identifying similarities and differences. From then on, the meaning of class became the same clan, and expanded to the same things or matter, and then gradually represented the 'resemblances' or 'similarity' [6].

People began to class the world by attributes since class has an abstract meaning, which is by the most simple and original activity of classification. Discrimination and differentiation is the starting point of logical thinking. It potentially has the law of identity and the law of contradiction, so it is the germination of logical thought. With the generation of classification, in terms of grasping a substance, firstly people will abstract concepts according to substances attributes, then tell from other things and make judgments; finally they can reason by the connotation and extension of the concept [6]. While thinking process includes the concept, proposition and reasoning as narrated above. This indicates the concept of class is the basis the logical thinking. Even Y. Zhou (1980) who studies the history of Chinese logic said that if the concept is the foundation of all science departments, then the class concept can be the basic logic of science. He considers that logic which is a universal law of human thinking science can't exist without the concept of class [7]. What he said is widely recognized in logic.

In logic, the sum of the concept's essential attributes, is called the concept of connotation. While the sum of the concept's subclasses is called the extension of the concept [8]. The class is a collection of things that are essentially the same, which means a collection of same concept connotation or the essential attributes of things. In fact, the process of forming a concept in mind is the process of classification, which is a process of cognition on concept extension. Class is the core concept of logic, while classification is the basis of logical reasoning activities as well as the distinction and understanding, and it is a logical method which can class a wide variety of things by grasping the essence of things or significant feature [9].

\subsection{Source of Classification}

Classification is a kind of cognitive activity. When mankind began to have practical activities, the divisions used to be an unconscious activity. With the increase of interaction between human and the objective, people's abstract ability is rising, and there is a conscious activity of classification. That is the idea of classification makes the first step which promotes human beings to separate themselves from the animals in the field of cognition [10]. Conscious classification activities mean that things in the minds firstly be abstracted into the concept, then forming a large class together with the connotation of the formation, and divided into smaller categories. This process is classification.

Classification is a research tool, which is a tool for human to study things after using classification to recognize things. Rectification of Names in Xunzi put forward that naming matters and identifying their essences can avoid many confusions. Identifying similarities and differences between things would not be bogged down abandoned disaster. So is academic research. If you want to have a systematic understanding of things, it is necessary to have a proper 
classification by studying and following its intrinsic attributes. There are many living examples which illustrate the world is studied by Classification, such as Periodic Table of the Elements, Kingdom, Phylum, Class, Order, Family, Genus, Species in biology and so on.

Classification is a kind of scientific research method, which synthesizes many kinds of logic methods. The classification method based on the external characteristics of things or the external connection is called the Phenomenon Classification. The virtue is that human can accomplish it easily. But usually things that are different in nature will be classified to the same category by the simplest method. Sothis method is also called Artificial Classification. For example, matters can be grouped into solid, liquid, gas and other forms of matter. However, the significance of this method is far less than the nature of the classification method. Classification according to the essential characteristics of things or internal links is an Essential Classification, often referred to as Natural Classification. For example, according to the material elements can group them into elements and compounds rather than the appearance of state. Classification in science should be natural classification. The development trend of classification is that from the phenomenon to the nature of classification and then to a more profound nature of classification [11].

Classification is a kind of special separation. As a kind of logical method, it has the rules that must be followed. (1) The principle of exhaustion. In classification, all extensions o $\mathrm{V} \mathrm{f}$ the parent item that is all the sub items contained in the concept should be found out. For example, when it comes to the classification of compound, compound should be classified into its exhaustive subclasses namely acid, base, salt or oxide. (2) The principle of mutual exclusion. The various items are independent of each other, can't cross. The divided sub items in addition to the above principles is the concept of all extension are reflected, each child should not overlap. It is not allowed to class the 'compound' into hydride, acid, base, salt and oxide. (3) The principle of identifiability. One standard should be followed in any classification. For example, 'compound' can't be divided into: metal compounds, acid and non metal oxides. A scholar analysis the classification of literary form in the new curriculum standard at length, he proposed to abolish the classification method because the classification criteria are not unified, the connotation of chaos, the extension is not clear [12]. It can be seen that the classification rules is the premise of scientific classification.

\section{Value of Classification}

\subsection{Classification Can Deepen the Understanding on the World}

People cannot suddenly understand and grasp the law of things in the world. However, the classification can deepen the understanding on the world, which shows great significance of the method. Early humans tried to sort things out when they tried to explore the laws of the world, such as China's Yin-Yang and Five Elements Theory (ancient China), Compendium of Materia Medica written by Shizhen Li (1518 $\sim 1593$ ), Aristotes's (about BC384 BC322) the theory of the Four Elements, Linne's (1707 1778) system classification of the animal and plant, etc. One of the major trends in the development of modern science is that subjects become more and more finely. There were 500 disciplines in 1900. The figure increased rapidly to 10 times in 2000 , even 100 times in 2100 [13].

Classification is a weapon in the understanding of the specific things. Substances in the same class have similar properties. A known substance can infer the nature and laws of the unknown substance. For example, $\mathrm{CO}_{2}$ belong to acidic oxides, as well as $\mathrm{SO}_{2} \cdot \mathrm{SO}_{2}$ will be able to understand why $\mathrm{SO}_{2}$ access to clarify lime water will become turbid, and why $\mathrm{SO}_{2}$ can make the wet litmus paper turns red and so on.

\subsection{Classification is Beneficial to the Construction of Information Framework}

Guangxian Xu (1920 2015), the Academicians of CAS, was inspired by the classification of traditional Chinese medicine classification, thinking that the knowledge must be classified storage. He believed that classification and archiving of information is conducive to storage, retrieval, memory, contact comparison, analysis, induction and innovation. He mentioned things that had a profound impact on his life: when he was a junior, he established the framework of physical chemistry, which made him successfully passed the examination to study staying in the United States in 1947 and the exam for teaching in Peking University in 1951 [14].

Information framework makes knowledge systematize and be ease of information extraction. Our thinking will be more clearly, relative and creative.

\subsection{Classification Can Help Human Foresee New Things}

Scientific classification can make the complex world systematize, and highlight the main features of things. Therefore human can grasp the essence of things, and foresee new things. Ultimately, the knowledge can be more abundant. For example, Mendeleyev (1834 1907) had boldly predicted gallium(Ga), scandium( $\mathrm{Sc})$ and germanium (Ge) after the discovery of Element Periodic Table; discovery of quark is Murray Gherman $(1929 \sim)$ deduced from the classification of baryons.

\subsection{Classification is Conducive to Thinking Innovation}

Innovation on scientific research is the outstanding and direct performance of innovative thinking. To a certain extent, classification can promote scientific research innovation, which reflects mainly in deepening the marginal study and expanding the interdisciplinary. Marginal scientific research is pioneering. Actually it is a kind of innovation. There are many scientists who won the Nobel prizes in marginal scientific research. Subject category system makes it easy to 
find out marginal scientific research then carry out, broaden its field, and realize the scientific innovation. Cross scientific research is a kind of exchange among different fields. It is a direct scientific research innovation. Classification is an effective tool to realize the scientific research. It can promote the production of the new proposition of scientific research.

The creations that shock of the world often result from academic thinking and theories on edge disciplines, and the crossing between disciplines. F. Sanger (1918 2013) got casual reminder from some Professors who devote themselves to physics, chemistry and biology. He developed the first sequencing method for analyzing DNA sequences with the help of the other two achievements. This work earned him recognition and a nomination for the Nobel Prize ultimately won by F. Sanger and in 1980, and it was second time for Sanger won the Nobel Prize in Chemistry [15]. The development of the world is also bringing more complex problems, and standing in a single perspective cannot solve the problem. In fact, science itself is a kind of classification. To achieve scientific innovation needs to collect knowledge with the classification method, study by category, look for creative inspiration in the branch point, and to use the methods of other types of material and so on.

\section{Application of Classification}

Any science begins with classification or selection. In fact, science itself has the meaning of "branch of science". It is difficult to deal with the whole universe at once. It is wise to choose a part of it to observe and study. So is chemistry. Thus, what is the application on classification in chemistry?

\subsection{Classification Can Promote the Establishment of the Theory of Chemistry}

In ancient time, the use of fire results in the burning of pottery, metallurgy and pharmaceutical. Advanced technology promotes the Yin-Yang and Five Elements Theory, the Theory of Four Elements, and atomism. With the development of modern industry, many theories were put forward such as Phlogiston Theory, Oxidation Theory, the Law of Conservation of Mass and Periodic Law of Elements. The above theories all indicate the thought of classification [16].

\subsection{Classification Can Promote the Establishment of Chemistry}

Classification can promote the establishment of chemistry. Chaotic element world became regular and orderly after classing, thus Inorganic Chemistry Theoretical System was basically formed. Analytical Chemistry itself is a subject to compare and classify substances. Because Guangxian Xu. et al. studied extracted chemical law by classified extraction system, Extraction Chemistry was formed. And combined with nuclear fuel of uranium, thorium, plutonium and extraction process of rare elements, the research method of extraction mechanism was improved and developed [17]. The development and formation of modern organic chemistry is one of typical examples which embody the function of classification. The Classification played an important role in modern Organic Chemistry formation and development, shown in the following main aspects.

(i) In the terms of clearing the research object of organic chemistry, organic matters were split off from the material world by the means of classification, and the concept of organic matters has been defined.

(ii) In the terms of the organic system, Theory of Types established the quite perfect classification of organic chemistry. It played an important role in the preparation of some substances and their chemical properties. The classification of simpler organic compounds was close to modern classification by functional groups such as haloalkane, alcohol and amine, etc. At that time, the organic compounds were divided into four types: the Ammonia Type, the Water Type, the Hydrogen Type, the Hydrochloric acid Type. If scientists substitute the hydrogen atom above the four types of substances with other atom or atomic group, there would be countless organic matters. Moreover, the concept of homologous series is very significant for organic chemistry. It is only necessary to know the reactions of one in order to predict those of the others.

(iii) In the terms of organic chemical structure theories, (a) The grouping theory was a harbinger of modern grouping theory; (b) Theory of Substitution and the Type Theory contributed to the law of organic substitution reaction. They helped to recognize the difference among organic matter and inorganic matter, and made a preliminary attempt in the classification of organic matter. All of this indicated that classification promoted the theoretical development of organic chemistry. (c) The Type theory had a certain effect on the proposal of atomic price. As the German chemist L. Meyer J. (1830 1895) said, Theory of Types played a great role in the development of the chemistry [18].

Thus, classification is important for the formation and development of a discipline, such as the study of object selection and establishment, the exploration of structure and properties and the development of the discipline theories.

\subsection{Predictability of Classification}

In the history of Chemistry, there will be a new discovery if people reason about a large number of sensitive materials by the means of classification and comparison. Class material according to the attribute, and then further study the composition of the material, structure, nature, etc., we can not only grasp the law, but also found new materials and create them. Furthermore, It is difficult for people to achieve many studies without the help of the Periodic Table, such as the discovery of new elements, the correction of atomic weight, the prediction of chemical reaction, research on new materials and so on. In the proof of $\mathrm{CH}_{4}$ molecule is spatial structure, at the first of all, J. H. Van't Hoff (1852 1911) synthesized a $\mathrm{CH}_{2} \mathrm{Cl}_{2}$. Then, he assumed that the molecules 
maybe have two structures, and the counterparts were ortho methylene chloride and para methylene chloride. $\mathrm{He}$ analyzed the hypothetical, and concluded that methane is a regular tetrahedral structure rather than a planar structure.

\section{Conclusion}

In short, teachers' literacy is the key to make each student an all-round one in the background of the promotion of the new curricular. In chemical study, the most important is to help students form the chemistry key competency. As a teacher, it is necessary to have a comprehensive understanding and deep recognition of the classification. There for, students can grasp classification method of the matters and its changes. They do the classification study from different perspectives on the complex chemical changes. Even accomplish the further goal to reveal the characteristics and laws of all kinds of changes. Teachers' attainment determines the key competency of students in learning chemistry, and affects their scientific literacy.

\section{Acknowledgment}

This thesis is a key project of education reform in Higher Education in Shaanxi Province in 2015: based on the concept of cooperative education for "the construction of outstanding teacher training system", it is the stage achievement [2015] 21 of higher education in Shaanxi Province. No. JSJY2015J009.

\section{References}

[1] Ministry of Education of the People's Republic of China (2011). The Compulsory Educational Chemistry Curriculum Criterion (2011Edition). Beijing: People's Education Press.

[2] Wang, Z. \&Wang, L. (2012). Understanding the Compulsory Educational Chemistry Curriculum Criterion (2011Edition). Beijing: Higher Education Press, pp. 213.

[3] Ministry of Education of the People's Republic of China (2003) Chemistry Curriculum Criterion of Ordinary Senior High School (experiment). Beijing: People's Education Press.

[4] Wang, P., Yang, C. \&Tan, X. (2013). An empirical study on the teaching of material knowledge based on the concept of classification. Chinese Journal of Chemical Education, 34(01), $32-34+41$
[5] Zhi, Y., Wang, L., \& Zhang, R., et al. (2012). The function value analysis and teaching realization of "material classification" to promote the study of the inorganic nature of high school students. Chinese Journal of Chemical Education, 33(04), 28-35.

[6] Chen, M. (1985). Seeing the germination of Chinese ancient logic thought and the establishment of the logical science from the perspective of the development of the concept of the class, mean while discussing with Wu, J. Social Sciences in China, 04, 117-127.

[7] Zhou, Y. (1980). On the properties and form of The Mohism's 'provide causes with reasons'. Journal of Sichuan University (philosophy and social science edition), 04:50-58.

[8] Yong, Q. (2007). The logic (fourth edition). Beijing: China University of Law Press, pp. 24-29.

[9] Shi, Y. (2014). Type-Logical Thinking and Type-Logical Thinking in Ancient Chinese Medicine. Yanshan University.

[10] Sun, Y. (2015). The Evolution and Sublimation of the Logical Relationship between the Classification Thought and the Scientific Research. Science and Technology Management Research, 35(01), 242-246.

[11] Xu, G. (1984). Classification methods in scientific research and molecular classification. University Chemistry, 04, $68-70+67$.

[12] Deng, M. (2014). Unscientific classification on New curriculum Style. Journal of Teaching and Management, 34, 83-84.

[13] Xu, G. (2010). Sixteen methods of scientific research innovation. China Awards for Science and Technology, 10, 23-25.

[14] Xu, G. (2004). My Understanding of Quality Education. University Chemistry, 19(03), 1-8.

[15] Liu, W., Ren, Z. \&Qin, C. (2004). The Mechanism, Ability and Regulation of University Interdisciplinary. Academic Degrees \& Graduate Education, 02, 8-12.

[16] Huang, R. \&Wu, X. (2008). Milestones in Chemistry. Beijing: Oriental Press, pp. 15-17.

[17] Xu, G., Wang, W. \& Wu, J. (1984). Principles of Extraction Chemistry. Shanghai: Shanghai Science and Technology Press, pp. 4.

[18] Carl Schorlemmer (1978). The Production and Development of Organic Chemistry. Trans. Pan, J., Beijing: Science Press, pp. 54. 